Check for updates

Cite this: J. Mater. Chem. C, 2021, 9, 3247

Received 1st October 2020,

Accepted 25th January 2021

DOI: $10.1039 / \mathrm{d0tc04676k}$

rsc.li/materials-c

\section{Novel spiro[fluorene-9,9'-xanthene]-based hole transport layers for red and green PHOLED devices with high efficiency and low efficiency roll-off $\uparrow$}

\author{
Tao Wang, ${ }^{a}$ Ming Shi, ${ }^{a}$ Daqi Fang, ${ }^{a}$ Junpeng He, ${ }^{a}$ Meng Zhang, ${ }^{\mathrm{b}}$ Siwei Zhang, ${ }^{\mathrm{b}}$ \\ Guodan Wei (D)*b and Hong Meng (D)*a
}

\begin{abstract}
Two N-phenyl-1-naphthylamine (PNA)/spiro[fluorene-9,9'-xanthene] (SFX) hybrid materials (DPNA-SFX and DOPNA-SFX) were successfully obtained by incorporating two PNA groups with a bridging phenyl ring to an SFX center. Both materials possess similar photophysical properties and an outstanding glasstransition temperature $\left(T_{\mathrm{g}}\right)$ beyond $150{ }^{\circ} \mathrm{C}$ surpassing that of most typical spirobifluorene and SFX materials. Both green and red phosphorescent organic light-emitting diodes (PHOLEDs) based on two materials achieved remarkable results. The DPNA-based green devices exhibited decent performance with the maximum current efficiency $\left(C E_{\max }\right)$, power efficiency $\left(P E_{\max }\right)$ and external efficiency $\left(E Q E_{\max }\right)$

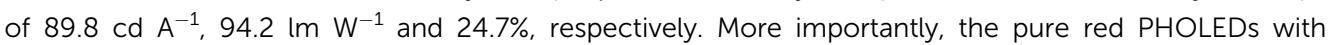
DPNA-SFX as the hole-transporting material achieved the $C E_{\max }, P E_{\max }$ and $E Q E_{\max }$ of $41.1 \mathrm{~cd} \mathrm{~A}^{-1}$, $46.4 \mathrm{Im} \mathrm{W}^{-1}$ and $34.7 \%$, respectively, which is comparable to those of the best red PHOLEDs. And the EQE at $1000 \mathrm{~cd} \mathrm{~m}^{-2}$ maintained $96 \%$ of its peak value, demonstrating an extremely low efficiency roll-off.
\end{abstract}

\section{Introduction}

Organic light-emitting diodes (OLEDs) have attracted extensive research interest both in academia and industry due to their superior merits such as wider viewing angle, lower energy consumption, light weight, excellent colour purity and mechanical flexibility. Within the past few years, OLEDs have been steadily well-developed and rapidly expanded in the mainstream display and solid-state lighting technology for consumer electronics. OLEDs are typically composed of multi-layered thin films sandwiched between two respective anode and cathode. Each organic layer is constructed for its own function, such as carrier injection layer (CIL), hole transporting layer (HTL), electron transporting layer (ETL), and emissive layer (EML), specifically designed for effective injection, the transport of the charge carriers and electron-hole balance in the emissive region. ${ }^{1-6}$ Therefore, OLED efficiency is predominantly determined by charge balance, the radiative decay of excitons and light outcoupling. Due to the relatively low intrinsic carrier concentrations of the transport layer,

\footnotetext{
${ }^{a}$ School of Advanced Materials, Peking University Shenzhen Graduate School, Peking University, Shenzhen, 518055, P. R. China

${ }^{b}$ Tsinghua-Berkeley Shenzhen Institute (TBSI), Tsinghua Shenzhen International Graduate School, Tsinghua University, Shenzhen, 518055, P. R. China

$\dagger$ Electronic supplementary information (ESI) available. See DOI: 10.1039/ dotc04676k
}

the current-voltage characteristic is injection-limited, and it requires balancing charge injection to improve the current performance of OLED devices. Useful and feasible HTL plays a critical role in improving electroluminescence efficiency since it directly relates the turn-on voltage of OLED, balancing hole transport and light-extraction efficiency. ${ }^{4,7-11}$

In general, hole transport materials (HTMs) need to possess strong thermal stability with high glass transition temperature $\left(T_{\mathrm{g}}\right)$, high hole mobility, morphologically stable thin films and an appropriate HOMO level to ensure a low energy barrier for hole injection and a suitable LUMO level to block electron injection from the emissive layer. Traditionally, commonly used HTLs are $N, N^{\prime}$-di(1-naphthyl)- $N, N^{\prime}$-diphenylbenzidine (NPB), $4,4^{\prime}$-bis[ $N$-( $p$-tolyl)- $N$-phenylamino]biphenyl (TPD), $N, N^{\prime}$ di(biphenyl-4-yl)-N, $N^{\prime}$-diphenyl-[1,1'-biphenyl]-4,4'-diamine ( $p$-BPD) and 1-bis[4-[N,N-di(4-tolyl)amino]phenyl]-cyclohexane (TAPC), due to their high hole mobility, suitable HOMO/LUMO energy levels and ease of sublimation. ${ }^{12-16}$ It is quite apparent that triarylamine (TPA) and its derivatives with a nitrogen atom connected with aromatic rings are excellent building blocks because of their good electron donating properties. ${ }^{17-24}$ In addition, HTMs are expected to have good thermal stability and morphological durability, which are conducive to OLED fabrication and operation. Introducing a bulky and rigid moiety into a molecule is a common strategy to increase thermal stability. ${ }^{24,25}$ The utilization of a spirocyclic structure endows HTMs with an intrinsic nonplanar three-dimensional 
architecture, which results in reduced intermolecular interactions, restricted crystallization tendency and increased molecule rigidity along with higher $T_{\mathrm{g}}{ }^{26-30}$

Spiro[fluorene-9,9'-xanthene] (SFX) is a famous spiro-type platform for one-pot synthesis to design new organic semiconductors for optoelectronic devices. ${ }^{31-38}$ For example, Zhang et al. synthesized and characterized several dicarbazole-substituted SFX-based molecules as host materials for blue and green PHOLEDs. ${ }^{39}$ Two similar SFX derivatives (SFX-Cr1 and SFX-Cr2) with tetra-carbazole substitution were reported by Wang and co-workers. SFX-Cr2 possesses a respectable $T_{\mathrm{g}}$ of $130{ }^{\circ} \mathrm{C}$ and a high hole mobility $\left(\sim 10^{-3} \mathrm{~cm}^{2} \mathrm{~V}^{-1} \mathrm{~s}^{-1}\right)$. Green PHOLEDs with SFX-Cr2 as the HTL showed a high EQE of $16.3 \% .^{40}$ Several compounds with carbazole, diphenylamine, $N, N^{\prime}$-di(4methoxyphenyl)amino, and phenothiazine motifs have been demonstrated as compromising HTMs for high-efficiency PSCs by replacing the corresponding moiety in commercialized spiroMeOTAD to the SFX core. ${ }^{41,42}$ Recently, the relationship between the thermal and redox properties of the HTMs and different modified positions of TPA groups as well as their further influence on PSC efficiency were also analyzed. ${ }^{43}$ Therefore, these reports have established solid progress in developing high-quality HTMs based on the SFX core for high-performance OLEDs.

However, poor thermal stability renders their low $T_{\mathrm{g}}$, thus leading to the detriment of device efficiency and lifetime. ${ }^{44-47}$ It is essential to further develop new types of HTMs to improve the OLED performance. In this work, we have designed two new hole transporting materials, spiro[fluorene-9,9'-xanthene]-2,7-di- $\left(N^{1}, N^{3}\right.$ di-1-naphthalenyl- $N^{1}, N^{3}$-diphenyl-1,3-benzenediamine) (DPNA-SFX) and spiro[fluorene-9, $9^{\prime}$-xanthene]-2' $7^{\prime}$-di- $\left(N^{1}, N^{3}\right.$-di-1-naphthalenyl$N^{1}, N^{3}$-diphenyl-1,3-benzenediamine) (DOPNA-SFX), applying the same SFX core with bridge phenyl rings at different positions (fluorene or xanthene core), which are meta-substituted by two electron-donating arylamine groups, $N$-phenyl-1-naphthylamine (PNA). It was found that both HTMs show relatively high $T_{\mathrm{g}}$ beyond $150{ }^{\circ} \mathrm{C}$, indicating dramatically enhanced thermal stability compared to NPB. The hole mobilities of DPNA-SFX and DOPNASFX are $7.6 \times 10^{-5} \mathrm{~cm}^{2} \mathrm{~V}^{-1} \mathrm{~s}^{-1}$ and $6.8 \times 10^{-5} \mathrm{~cm}^{2} \mathrm{~V}^{-1} \mathrm{~s}^{-1}$, respectively, both of which are superior to those of NPB. All the multilayer green and red PHOLEDs exhibit superb efficiency data with a low turn-on voltage when adopting new HTLs. The DPNA-based green OLED device represents the greatest green device with CE, PE and EQE peaks of $89.8 \mathrm{~cd} \mathrm{~A}^{-1}, 94.2 \mathrm{~lm} \mathrm{~W}^{-1}$ and $24.7 \%$. More significantly, the DPNA-based red device R1 displays outstanding performance with the CE, PE and EQE peaks of $41.1 \mathrm{~cd} \mathrm{~A}^{-1}, 46.4 \mathrm{~lm} \mathrm{~W}^{-1}$ and $34.7 \%$, which is comparable to the world record of red PHOLEDs. And the EQE of the device R1 at $1000 \mathrm{~cd} \mathrm{~m}^{-2}$ maintained $96 \%$ of its highest value, which shows an extremely low efficiency roll-off in pure red PHOLED devices.

\section{Results and discussion}

\section{Synthesis and thermal properties}

All the chemical structures and the synthetic processes of the target compounds are shown in Scheme 1. The main
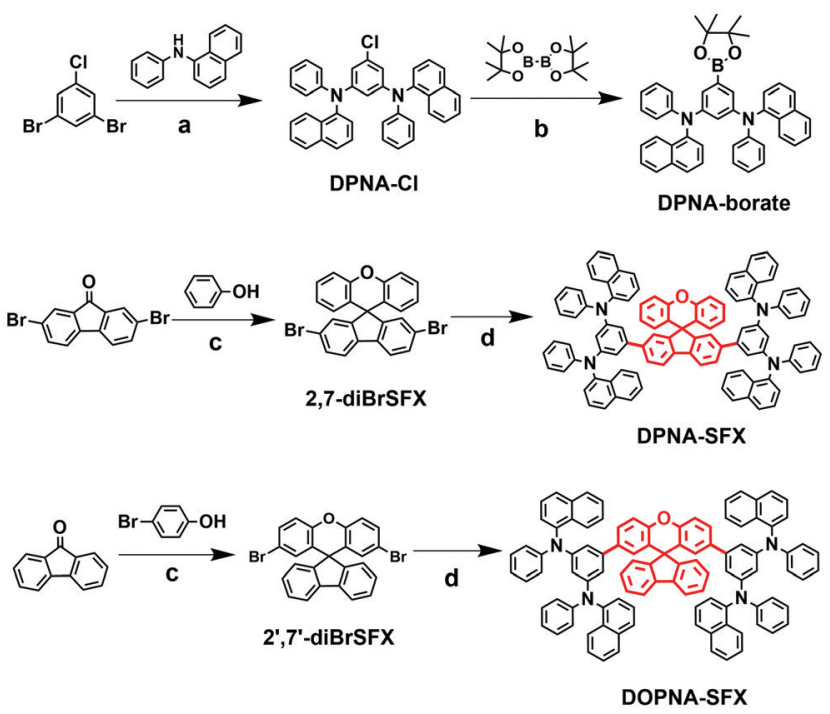

(a) tBu-ONa, (A-taPhos) $)_{2} \mathrm{PdCl}_{2}$, Toluene, reflux, $8 \mathrm{~h}$;

(b) $\mathrm{Pd}_{2}(\mathrm{dba})_{3}$, Xphos, KOAc, 1,4-dioxane, reflux, 12h;

(c) $\mathrm{CH}_{3} \mathrm{SO}_{3} \mathrm{H}, 150^{\circ} \mathrm{C}, 24 \mathrm{~h}$;

(d) DPNA-borate, (A-taPhos) ${ }_{2} \mathrm{PdCl}_{2}, \mathrm{~K}_{2} \mathrm{CO}_{3}$, Toluene/ $\mathrm{H}_{2} \mathrm{O}$, reflux, $12 \mathrm{~h}$.

Scheme 1 Synthetic routes of DPNA-SFX and DOPNA-SFX.

intermediates and the final products were synthesized using common methods published in the literature. ${ }^{40}$ All of the compounds were confirmed by ${ }^{1} \mathrm{H}-\mathrm{NMR},{ }^{13} \mathrm{C}-\mathrm{NMR}$ and highresolution mass spectrometry (HR-MS).

To determine the thermal properties and morphological stabilities of the synthesized HTMs, differential scanning calorimetry (DSC) and thermogravimetric analysis $\left(T_{\mathrm{g}} \mathrm{A}\right)$ were measured under a nitrogen atmosphere, as depicted in Fig. S5 (see the ESI $\dagger$ ). The decomposition temperature $\left(T_{\mathrm{d}}\right)$ and glass transition temperature $\left(T_{\mathrm{g}}\right)$ values are summarized in Table 1. The $T_{\mathrm{d}}$ values were found to be $543{ }^{\circ} \mathrm{C}$ and $535{ }^{\circ} \mathrm{C}$ for DPNA-SFX and DOPNA-SFX, respectively, indicating the excellent thermal stability of both compounds due to the rigidity of the spiro molecular structure. According to the DSC curves, a clear glass transition phenomenon can be observed with the $T_{\mathrm{g}}$ values of DPNA-SFX and DOPNA-SFX up to $151^{\circ} \mathrm{C}$ and $153^{\circ} \mathrm{C}$, respectively, suggesting it is beneficial to form continuous thin films compared with the typical hole transporting material NPB with a $T_{\mathrm{g}}$ of $95{ }^{\circ} \mathrm{C}$. Moreover, the PL spectra of thin films of three HTMs under different temperatures have been measured (see Fig. S6, ESI $\dagger$ ). The PL spectra of DPNA-SFX and DOPNA-SFX remain consistent even under $300{ }^{\circ} \mathrm{C}$; however, the PL intensity relative to that under room temperature of NPB has been largely decreased, which indicates the better thermal stability of our HTMs than NPB.

\section{Electrochemical properties and theoretical calculations}

To investigate the electrochemical behaviour of DPNA-SFX and DOPNA-SFX, cyclic voltammetry (CV) measurements were conducted with $\mathrm{Ag} / \mathrm{AgCl}$ as the reference electrode. The $\mathrm{CV}$ curves are displayed in Fig. S7 (see the ESI $\dagger$ ) and the corresponding data are summarized in Table 1, indicating the same CV profile for DPNA-SFX and DOPNA-SFX with similar oxidation couples 
Table 1 The thermal, photophysical and electrochemical properties of DPNA-SFX and DOPNA-SFX

\begin{tabular}{|c|c|c|c|c|c|c|c|}
\hline \multirow[b]{2}{*}{ Compound } & \multirow[b]{2}{*}{$T_{\mathrm{d}}{ }^{a} / T_{\mathrm{g}}{ }^{b}$} & \multirow[b]{2}{*}{$\lambda_{\mathrm{abs}}{ }^{c}$} & \multirow[b]{2}{*}{$\lambda_{\mathrm{em}, \mathrm{s}}{ }^{c} / \lambda_{\mathrm{em}, \mathrm{f}}{ }^{d}$} & \multicolumn{2}{|c|}{ HOMO/LUMO $(\mathrm{eV})$} & \multirow[b]{2}{*}{$E_{\mathrm{e}}^{g}(\mathrm{eV})$} & \multirow[b]{2}{*}{$E_{\mathrm{T}}^{h}(\mathrm{eV})$} \\
\hline & & & & Exp. $^{e}$ & $\mathrm{Cal}^{f}$ & & \\
\hline DPNA-SFX & $543 / 151$ & 308 & $447 / 429$ & $-5.23 /-1.98$ & $-4.87 /-1.37$ & 3.25 & 2.45 \\
\hline DOPNA-SFX & $535 / 153$ & 297 & $435 / 420$ & $-5.23 /-2.03$ & $-4.85 /-1.45$ & 3.20 & 2.44 \\
\hline
\end{tabular}

and no reduction process. Both DPNA-SFX and DOPNA-SFX show good stability of electrochemical oxidation. During the anodic scan in the DCM solution, two HTMs exhibit four quasi-reversible, four electron oxidation processes, which can be assigned to the oxidation of four 1-( $N$-phenylamino)naphthalene units. The HOMO energy levels are determined from the onset of the oxidation curve using the empirical formula, which is at the same value of $-5.23 \mathrm{eV}$ for both materials, deeper than the HOMO level of NPB $(-5.12 \mathrm{eV})$, benefiting the promotion of hole injection. On the other hand, the LUMO energy level can be calculated using the HOMO energy level and band gap $\left(E_{\mathrm{g}}\right)$, which are thus $-1.98 \mathrm{eV}$ and $-2.03 \mathrm{eV}$, respectively. To have a better understanding of the electronic structures of DPNA-SFX and DOPNA-SFX, density functional theory (DFT) calculations were conducted to simulate the frontier molecular orbital (FMO) levels and spatial distributions (Fig. 1(a)). The DFT results show that the HOMOs of both molecules are mainly localized at the two PNA moieties and the bridge phenyl ring, and the calculated HOMOs show no big difference which is in agreement with the experimental results. However, the LUMO of DPNA-SFX is distributed in the fluorene part of the SFX core and the bridge phenyl ring, while that of DOPNA-SFX is just located at the PNA moiety due to the breakdown of conjugation extension by the xanthene moiety.

\section{Photophysical properties}

To investigate the photophysical behaviours of the new HTMs, UV-Vis absorption spectra and photoluminescence (PL) spectra in dilute dichloromethane (DCM) solution and thin film, as well as phosphorescence spectra in DCM at $77 \mathrm{~K}$ were recorded respectively, and are shown in Fig. 1(b) and (c), and the summarized data are presented in Table 1. For both DPNASFX and DOPNA-SFX, the strongest absorption bands around $300 \mathrm{~nm}$ are attributed to localized transitions associated with the PNA core. In the UV-Vis spectra of DPNA-SFX, a shoulder absorption peak was observed at $320 \mathrm{~nm}$ due to the $\pi-\pi^{*}$ transition from the PNA moiety to the fluorene moiety. The longer wavelength band at $350 \mathrm{~nm}$ with weaker absorption of DOPNA-SFX could be assigned to the $\pi-\pi^{*}$ transition from the PNA moiety to the xanthene moiety, revealing the formation of the intramolecular charge transfer (ICT) state made by some degree of weaker spiro-conjugation effect. In addition, the band gaps $\left(E_{\mathrm{g}}\right)$ are estimated from the absorption edge, which are $3.25 \mathrm{eV}$ and $3.20 \mathrm{eV}$ for DPNA-SFX and DOPNA-SFX, respectively. Both compounds show blue emission in dichloromethane (DCM) and their maximum emission peaks were at $447 \mathrm{~nm}$ (a)
DPNA-SFX

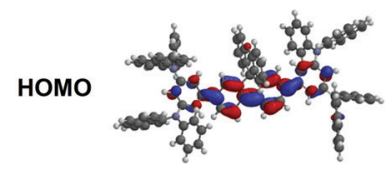

$-1.24 \mathrm{eV}$

LUMO

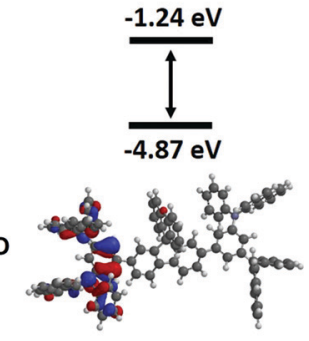

(b)

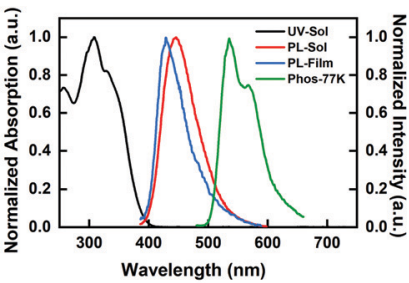

DOPNA-SFX

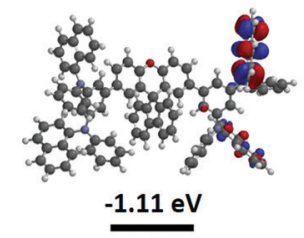

$\frac{\uparrow}{4.85 \mathrm{eV}}$

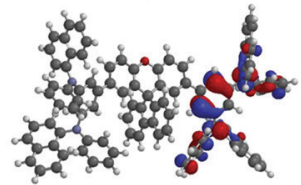

(c)
Fig. 1 (a) HOMO and LUMO distributions of DPNA-SFX and DOPNA-SFX; (b and c) UV-Vis absorption (in DCM solution), PL spectra (in DCM solution and in film at room temperature, in DCM solution at $77 \mathrm{~K}$ ) of (b) DPNA-SFX; and (c) DOPNA-SFX.

and $435 \mathrm{~nm}$, respectively. The maximum wavelength of DPNA-SFX exhibits a $14 \mathrm{~nm}$ red-shift relative to DOPNA-SFX, which could be due to the extended conjugation of DPNA-SFX. The fluorescence spectra of two HTMs reveal a solvatochromic effect (see Fig. S8, ESI $\dagger$ ), which indicates that DPNA-SFX and DOPNA-SFX are slightly sensitive to solvent polarity. To measure the triplet energy of the two HTMs, low temperature phosphorescence spectra ( $77 \mathrm{~K}$, in DCM solution) were collected under a nitrogen atmosphere (shown in Fig. 1(b) and (c)), corresponding to $T_{1}$ of $2.45 \mathrm{eV}$ and $2.44 \mathrm{eV}$ (Table 1), respectively, which are both higher than NPB $(2.33 \mathrm{eV})$. Higher $T_{1}$ guarantees better exciton confinement in terms of OLED device structure.

\section{Single carrier devices}

Single carrier devices of DPNA-SFX and DOPNA-SFX were fabricated to study the corresponding hole-transporting properties, 
according to the architecture of ITO/HAT-CN (10 nm)/DPNA-SFX or DOPNA-SFX $(100 \mathrm{~nm}) / \mathrm{HAT}-\mathrm{CN}(10 \mathrm{~nm}) / \mathrm{Al}(100 \mathrm{~nm})$, in which HAT-CN was used as the hole injection layer and electron blocking layer (inserted picture in Fig. 2(a)). No electroluminescence phenomenon was detected during measurement implying these are singlet-only devices. The $J-V$ curves of the hole-only devices in Fig. 2(a) reveal that the current densities at the same voltage follow the sequence: DPNA-SFX $>$ DOPNA-SFX $>$ NPB. The difference between the curves could further indicate that, according to the HOMO energy level of HAT-CN and the above HTMs, a better charge injection from HAT-CN could be achieved in DPNA-SFX and DOPNA-SFX based devices than in the NPBbased one.

Space charge limited current (SCLC) theory can be used to evaluate the carrier mobility of semiconductors when quasiOhmic contacts between the metal electrode and organic layer are well established, which gives the formula: $J=9 \varepsilon_{0} \varepsilon_{\mathrm{r}} \mu E^{2} / 8 L$. Considering the electric-field-dependent charge mobility of organic semiconductors according to Poole-Frenkel mechanics $\left(\mu=\mu_{0} \exp (\beta \sqrt{E})\right)$, the expression can be written as

$$
J=9 \varepsilon_{0} \varepsilon_{\mathrm{r}} \mu_{0} E^{2} \exp (\gamma \sqrt{E}) / 8 L
$$

where $\varepsilon_{0}$ is the permittivity of vacuum $\left(\sim 8.85 \times 10^{-12} \mathrm{~F} \mathrm{~m}^{-1}\right), \varepsilon_{\mathrm{r}}$ is the relative dielectric constant, which equals three for the organic materials approximately, $\mu_{0}$ is the zero-field charge mobility, $\gamma$ is the Poole-Frenkel factor, and $L$ and $E$ are the thickness of the organic layer and the electric field, respectively. ${ }^{6}$

The value of $\mu_{0}$ and $\gamma$ was determined from the $J-V$ curves by the linearization of the equation above, which is $7.6 \times 10^{-5} \mathrm{~cm}^{2} \mathrm{~V}^{-1} \mathrm{~s}^{-1}$, double helical C/Co@CNT nanocomposite with hierarchical structures for enhancing microwave absorption for DPNASFX, $6.3 \times 10^{-5} \mathrm{~cm}^{2} \mathrm{~V}^{-1} \mathrm{~s}^{-1}, 1.48 \times 10^{-2} \mathrm{~V}^{-1 / 2} \mathrm{~cm}^{1 / 2}$ for DOPNA-SFX and $2.8 \times 10^{-5} \mathrm{~cm}^{2} \mathrm{~V}^{-1} \mathrm{~s}^{-1}, 1.38 \times 10^{-2} \mathrm{~V}^{-1 / 2} \mathrm{~cm}^{1 / 2}$ for NPB. It can be clearly observed that the zero-field mobilities show the following sequence: DPNA-SFX > DOPNA-SFX > $\mathrm{NPB}$, which indicates the better hole-transporting properties of the synthesized HTMs and the potential replacement for commercialized NPB. The hole mobility dependent on the electric field ascribed to the materials can be calculated with the two parameters, with the results depicted in Fig. 2(b). It is obviously shown that the hole mobilities increased rapidly at a high bias voltage. At the high electric field of $1.9 \times 10^{5} \mathrm{~V} \mathrm{~cm}^{-1}$, (a)

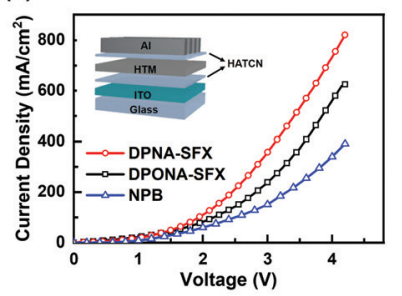

(b)

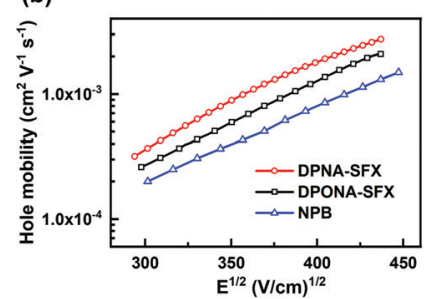

Fig. 2 (a) $J-V$ curves of the hole-only devices and (b) comparative field dependence mobility of DPNA-SFX and DOPNA-SFX. the hole mobilities of DPNA-SFX and DOPNA-SFX reach $2.75 \times$ $10^{-3} \mathrm{~cm}^{2} \mathrm{~V}^{-1} \mathrm{~s}^{-1}$ and $2.1 \times 10^{-3} \mathrm{~cm}^{2} \mathrm{~V}^{-1} \mathrm{~s}^{-1}$, respectively. High hole-transporting mobility with good hole injection ability renders DPNA-SFX and DOPNA-SFX as potential HTM candidates for application in OLEDs.

\section{PHOLED performance}

To evaluate the practical application for phosphorescent organic light-emitting diodes (PHOLEDs), green and red devices using the new HTMs were fabricated. Control devices were fabricated with the commonly-used HTL of $N, N^{\prime}$ bis(naphthalen1-yl)- $N, N^{\prime}$-bis(phenyl)-benzidine (NPB). The optimized PHOLED device structure is ITO/HAT-CN (5 nm)/HTM (30 nm)/Spiro-3-BFP $(10 \mathrm{~nm}) /$ DMIC-TRZ: DMIC-CZ: emitter $(40 \mathrm{~nm}) / \mathrm{ANT}-\mathrm{BIZ}(70 \mathrm{~nm}) / \mathrm{Liq}(2.5 \mathrm{~nm}) / \mathrm{Al}(100 \mathrm{~nm})$ (the HTM is DPNA-SFX for device G1, R1; DOPNA-SFX for device G2, R2), with $\operatorname{Ir}(\text { ppy })_{2}(\mathrm{acac}) \quad$ ([bis(2-phenylpyridine)(acetylacetonato) iridium(III)]) and Ir(dmpibq) $)_{2}$ (acac) (bis[2-(3,5-dimethylphenyl)5-isobutylquinoline-C2, $\left.\mathrm{N}^{\prime}\right]$ (acetylacetonato)iridium(III)) as the dopant for green and red emitting layers, respectively. In these devices, HAT-CN (dipyrazino[2,3-f: $\left.2^{\prime}, 3^{\prime}-h\right]$ quinoxaline-2,3,6,7, 10,11-hexacarbonitrile) and Liq (8-quinolinolato lithium) were used as the hole-injection and electron-injection materials, respectively. Spiro-3-BFP ( $N$-([1,1'-biphenyl]-2-yl)- $N$-(9-dimethyl$9 H$-fluoren-2-yl)-9,9'-spirobi[9H-fluoren]-4-amine) was used as the electron-blocking material to balance the electrons and holes for green and red devices. In the emitting layer, DMICTRZ (5-(3-(4,6-diphenyl-1,3,5-triazin-2-yl)phenyl)-7,7-dimethyl-5, 7-dihydroindeno[2,1-b]carbazole) and DMIC-CZ (7,7-dimethyl-5phenyl-2-(9-phenyl-9H-carzole-3-yl)-5,7-dihydroindeno[2,1-b]carbazole) served as the co-host system with a molar ratio of $1: 1$ for both green and red PHOLEDs, and the doping concentrations of $\operatorname{Ir}(\text { ppy })_{2}($ acac $)$ and $\operatorname{Ir}(d m p i b q)_{2}($ acac $)$ were $5 \mathrm{wt} \%$ and $2.5 \mathrm{wt} \%$, respectively. ANT-BIZ (1-(4-(10-([1,1'-biphenyl]-4-yl)anthracen-9yl)phenyl)-2-ethyl-1 $H$-benzo[ $d]$-imidazole) was employed as the electron-transporting material. The device configuration and energy level diagram and the corresponding molecule structures are shown in Fig. 3(a) and (b) and Fig. S9 (ESI + ). The device performance of the green and red PHOLED devices, including current density-voltage-luminance $(J-V-L)$ curves, current efficiency (CE), power efficiency (PE) and external quantum efficiency (EQE) versus luminance (L) curves, as well as the EL spectra are shown in Fig. 3. All the key device parameters are listed in Table 2.

As depicted in Fig. 3(c), both devices G1 and G2 emit green light with roughly identical emission peaks at $521 \mathrm{~nm}$ and $524 \mathrm{~nm}$, respectively, which was ascribed to $\operatorname{Ir}(\text { ppy })_{2}$ (acac) by efficient energy transfer from co-hosts to the guest. The EL spectra remain unchanged over a wide range of operating voltage from $3 \mathrm{~V}$ to $7 \mathrm{~V}$ (see Fig. S10, ESI $\dagger$ ). The corresponding CIE coordinates are $(0.32,0.62)$ and $(0.33,0.62)$, respectively. The two devices exhibited a comparatively low turn-on voltage of $2.4 \mathrm{~V}$ simultaneously (determined from Fig. 3(d)). It is apparently demonstrated that the device $\mathrm{G} 1$ has better device performance, with the maximum CE, $\mathrm{PE}$ and EQE of $89.8 \mathrm{~cd} \mathrm{~A}^{-1}$, $94.2 \mathrm{~lm} \mathrm{~W}^{-1}$ and $24.7 \%$, respectively, compared with the 
(a)

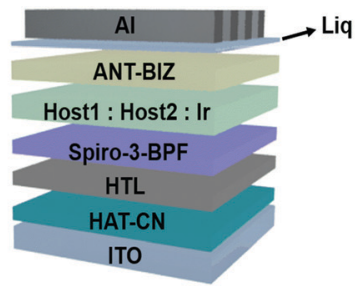

(d)

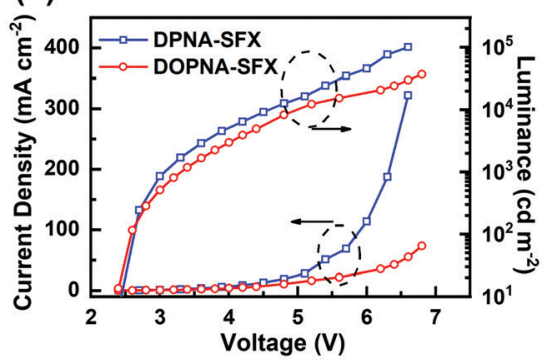

(b)

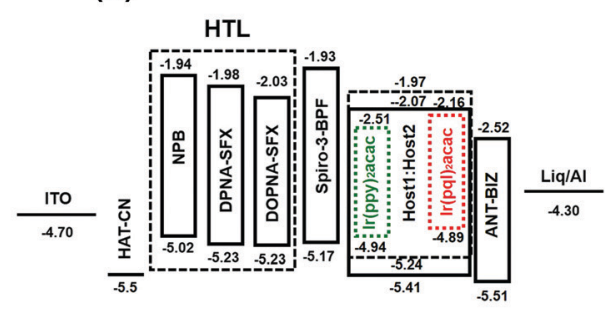

(e)

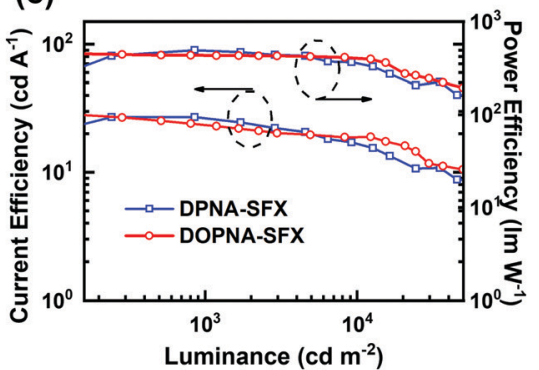

(c)

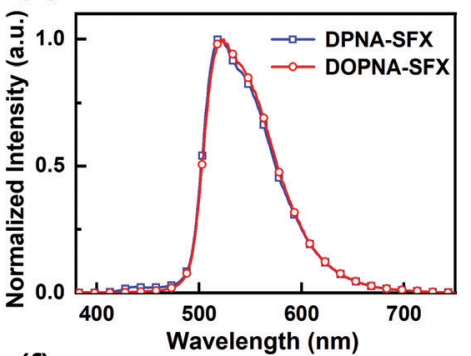

(f)

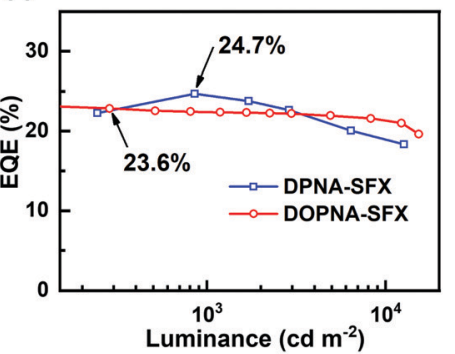

Fig. 3 (a) Device architecture of PHOLEDs and (b) energy diagram of multilayer PHOLEDs. Device performances of green PHOLEDs: (c) EL spectra (4.0 V), (e) $J-V-L$ curves, (f) $C E-L-P E$ curves, and (g) EQE- $L$ curves.

Table 2 Key electroluminescent properties of devices G1-G2 and R1-R2

\begin{tabular}{|c|c|c|c|c|c|}
\hline & & $\mathrm{CE}^{b}\left(\mathrm{~cd} \mathrm{~A}^{-1}\right)$ & $\mathrm{PE}^{c}\left(\operatorname{lm~} \mathrm{W}^{-1}\right)$ & $\operatorname{EQE}^{d}(\%)$ & \\
\hline Devices & $\begin{array}{l}V_{\mathrm{on}}{ }^{a} \\
(\mathrm{~V})\end{array}$ & $\begin{array}{l}\operatorname{Max} / 10^{3} / 10^{4} \\
\left(\mathrm{~cd} \mathrm{~m}^{-2}\right)\end{array}$ & $\begin{array}{l}\operatorname{Max} / 10^{3} / 10^{4} \\
\left(\mathrm{~cd} \mathrm{~m}^{-2}\right)\end{array}$ & $\begin{array}{l}\operatorname{Max} / 10^{3} / 10^{4} \\
\left(\mathrm{~cd} \mathrm{~m}^{-2}\right)\end{array}$ & $\mathrm{CIE}^{e}$ \\
\hline G1 & 2.4 & $89.8 / 88 / 72.2$ & $94.2 / 90 / 50.4$ & 24.7/24.2/19.9 & $(0.32,0.62)$ \\
\hline G2 & 2.4 & $85.6 / 81.4 / 70.5$ & $93.2 / 76.5 / 54.5$ & $23.6 / 22.4 / 21.4$ & $(0.33,0.62)$ \\
\hline $\mathrm{R} 1$ & 2.2 & $41.1 / 39.5 / 31.6$ & $46.4 / 29.6 / 15.5$ & $34.7 / 33.3 / 13.1$ & $(0.66,0.34)$ \\
\hline $\mathrm{R} 2$ & 2.2 & $31.4 / 26.5 / 25.4$ & $35.6 / 18.5 / 13.8$ & $25.1 / 21.2 / 20.3$ & $(0.66,0.34)$ \\
\hline
\end{tabular}

${ }^{a}$ Turn-on voltage at $1 \mathrm{~cd} \mathrm{~m}^{-2} \cdot{ }^{b}$ Current efficiency at maximum values/ $1000 \mathrm{~cd} \mathrm{~m}^{-2} / 10000 \mathrm{~cd} \mathrm{~m}^{-2}$. ${ }^{c}$ Power efficiency at maximum values/ $1000 \mathrm{~cd} \mathrm{~m}^{-2} / 10000 \mathrm{~cd} \mathrm{~m}^{-2}$. ${ }^{d}$ External quantum efficiency at maximum values/1000 $\mathrm{cd} \mathrm{m}^{-2} / 10000 \mathrm{~cd} \mathrm{~m}^{-2}$. ${ }^{e}$ CIE coordinates at $1000 \mathrm{~cd} \mathrm{~m}^{-2}$.

corresponding data of device G2 (85.6 $\mathrm{cd} \mathrm{A}^{-1}, 93.2 \mathrm{~lm} \mathrm{~W}^{-1}$ and $23.6 \%$ ). This is chiefly attributed to the higher hole mobility of DPNA-SFX and more harmonious charge recombination inside device G1. It is noteworthy that the green devices based on DPNA-SFX and DOPNA-SFX are both far better than the NPB-based PHOLEDs (68.5 $\mathrm{cd} \mathrm{A}^{-1}, 79.7 \mathrm{~lm} \mathrm{~W}^{-1}$ and 18.7\%) shown in Fig. S12 and Table S1 (ESI $\dagger$ ), which is presumably due to the imbalance of hole/electron injection and transport. The efficiency roll-off values of green PHOLEDs based on DPNA-SFX, DOPNA-SFX and NPB are $2 \%, 5 \%$ and $1 \%$. As we can see, both green devices show a relatively low efficiency roll-off. Sure, the roll-off of the NPB-based device is the lowest one, and the EQE is far behind that of the others.

The device performance of the red PHOLED devices based on DPNA-SFX and DOPNA-SFX was also measured (see Fig. 4). As shown in Fig. 4(a), the devices R1 and R2 present saturated red emissions with the same maximum peak of $620 \mathrm{~nm}$, with the CIE coordinates of $(0.66,0.34)$. The EL spectra remain unchanged over a wide range of operating voltage from $3 \mathrm{~V}$ to $7 \mathrm{~V}$ (see Fig. S11, ESI $\dagger$ ). The $J-V-L$ curve of the red devices indicates that the turn-on voltage of R1 and R2 is as low as $2.2 \mathrm{~V}$. The DPNA-SFX based device possesses a superb device performance, with a CE of $41.1 \mathrm{~cd} \mathrm{~A}^{-1}$, a PE of $46.4 \mathrm{~lm} \mathrm{~W}^{-1}$, and an EQE of $34.7 \%$, which completely outperforms that of the other one. The EQE of the DPNA-based red device is almost $40 \%$ higher than that of the NPB-based one. To the best of our knowledge, this excellent device performance is comparable with the best records of pure red PHOLEDs ${ }^{48-57}$ (some representative EQE values of red PHOLEDs are shown in Fig. 5). The efficiency roll-off values of red PHOLEDs based on DPNA-SFX, DOPNA-SFX and NPB are 4\%, 16\% and 30\%, respectively. To note, the device R1 also shows better efficiency roll-off compared with that of R2. It retains an EQE of 33.3\% even at $1000 \mathrm{~cd} \mathrm{\textrm {m } ^ { - 2 }}$, which is also significantly superior compared with those of R2 and the NPB-based device. Therefore, the DPNA-SFX based red device possesses an extremely high EQE and low roll-off compared with DOPNA-SFX and NPB. It is worth mentioning that we have also tested the devices using an integrating sphere in order to exclude the possibility of anisotropic emission of the green and red emitters. Almost similar results were exhibited (shown in Fig. S17 and S18, ESI $\dagger$ ), which indicates the impossibility of anisotropic emission of green and red emitters which might cause an overestimated performance.

In order to explore the possibility of high performance blue PHOLEDs, we fabricate blue devices based on the architecture of ITO/HAT-CN (5 nm)/HTM (40 nm)/TCTA (10 nm)/TCTA: TmPyPB:FIrpic $(20 \mathrm{~nm}) / \mathrm{TmPyPB} \quad(30 \mathrm{~nm}) / \mathrm{Liq} \quad(2.5 \mathrm{~nm}) / \mathrm{Al}$ $(100 \mathrm{~nm})$. The devices performance is shown in Fig. S13 (ESI $\dagger$ ) and all the key parameters are listed in Table S2 (ESI $\dagger$ ). Three kinds of devices possess a low turn-on voltage of $2.8 \mathrm{~V}$. The DPNA-SFX based device exhibits the best CE, PE and EQE of $17.93 \mathrm{~cd} \mathrm{~A}^{-1}, 14.87 \mathrm{~lm} \mathrm{~W}^{-1}$ and $8.70 \%$, respectively. Comparing 
(a)

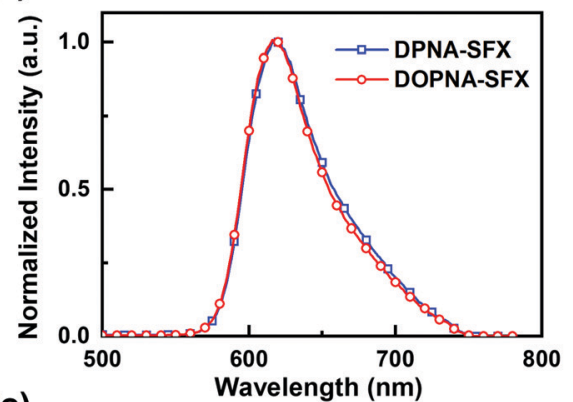

(c)

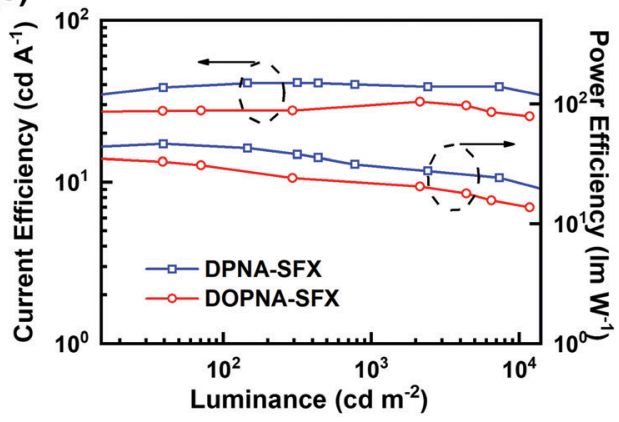

(b)

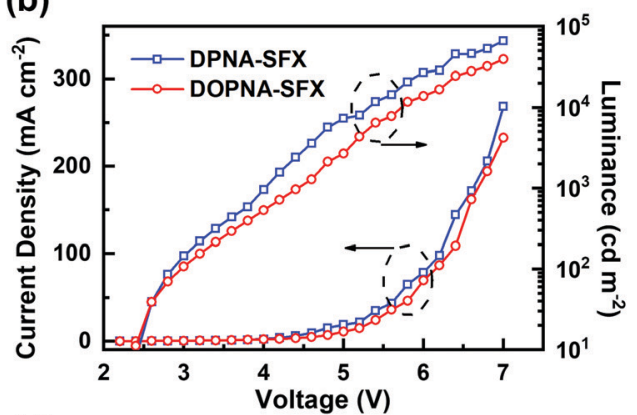

(d)

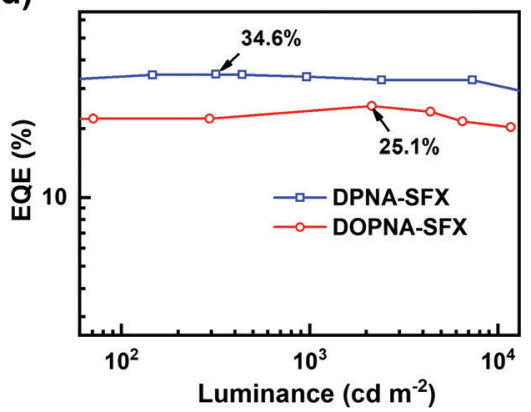

Fig. 4 Device performance of red PHOLEDs: (a) EL spectra (4.0 V), (b) $J-V-L$ curves, (c) CE- $L-P E$ curves, and (d) EQE- $L$ curves.

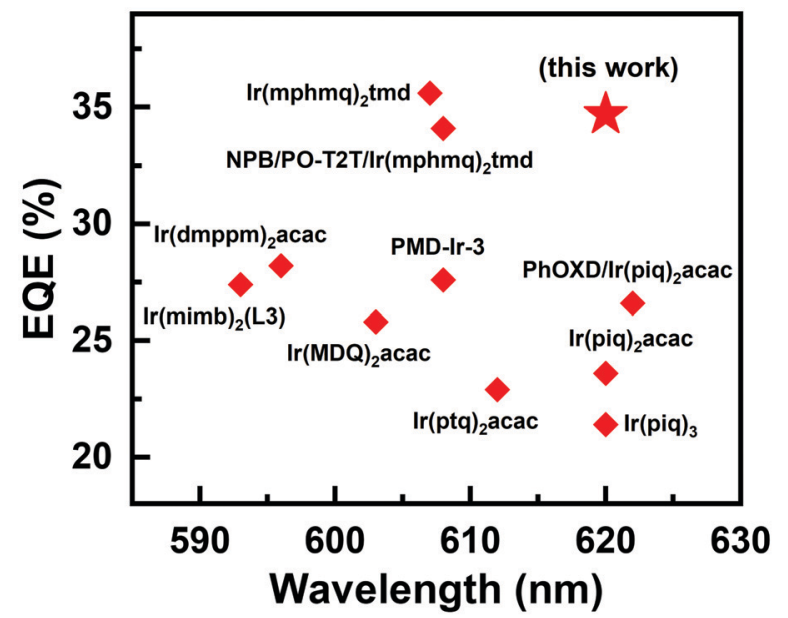

Fig. 5 EQE versus EL peaks of red PHOLEDs based on several representative iridium complexes.

with the NPB-based device, the performance of the DPNA-SFX and DOPNA-SFX based devices is much better, demonstrating their potential to replace commercialized HTMs.

Besides high efficiency, a long lifetime of PHOLEDs is also essential and is affected by the charge balance. We have confirmed the better thermal stability of our HTMs compared with NPB, which should contribute to the operational stability of the corresponding PHOLEDs as well. The lifetime of red and green PHOLEDs with the best EQE was evaluated. The lifetime curves shown in Fig. 6 of the green and red PHOLEDs were measured at a high initial luminance of $50000 \mathrm{~cd} \mathrm{~m}^{-2}$ and $10000 \mathrm{~cd} \mathrm{~m}^{-2}$, respectively. The DPNA-SFX and DOPNA-SFX (a)

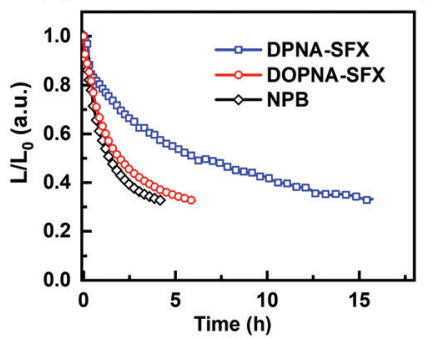

(b)

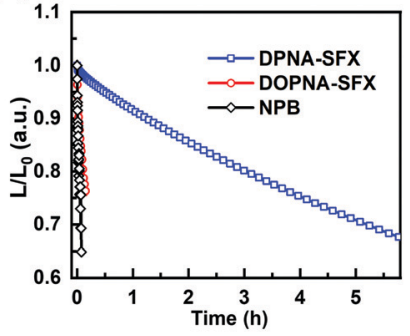

Fig. 6 Normalized luminance as a function of operating time for (a) red and (b) green PHOLEDs with different HTMs.

based red and green devices showed a longer lifetime than NPB, especially the DPNA-SFX based ones, indicating that the crucial role of the thermal stability of HTMs and much better charge balance render a longer lifetime for PHOLEDs.

To reveal the reasons for superb PHOLED performance, electron-only devices based on ANT-BIZ have also been fabricated ITO/Liq $(10 \mathrm{~nm}) /$ ANT-BIZ $(100 \mathrm{~nm}) / \mathrm{Liq}(10 \mathrm{~nm}) / \mathrm{Al}$ $(100 \mathrm{~nm})$ (see Fig. S14, ESI $\dagger$ ). The calculated electron mobility under zero electric field is $2.4 \times 10^{-4} \mathrm{~cm}^{2} \mathrm{~V}^{-1} \mathrm{~s}^{-1}$, which is higher than the hole mobilities of the applied HTMs. Considering the sequences of hole-transporting properties of DPNA-SFX, DOPNA-SFX and NPB, the DPNA-based PHOLEDs exhibiting the best device performance could be attributed to more efficient charge injection and better charge transport balance, which guarantee good exciton confinement. It is also in accordance with the optimization results of the thickness of the ETL layers (Table $\mathrm{S} 3, \mathrm{ESI} \dagger)$. In addition, we also fabricate two single carrier devices based on our PHOLED architecture without the emitting layers. 
The structures of the hole-only and electron-only devices are ITO/ HAT-CN (5 nm)/HTM (30 nm)/Spiro-3-BFP (10 nm)/Al and ITO/ ANT-BIZ (70 nm)/Liq (2.5 nm)/Al (100 nm) (see Fig. S15, ESI $\dagger)$. It is apparent that the mobility of three HTMs show the same sequence: DPNA-SFX > DOPNA-SFX > NPB. Similarly, the electron transporting properties of ANT-BIZ are better than those of HTMs, thus DPNA-SFX possesses the best performance because of better charge balance.

According to the device performance of green and red PHOLEDs, respectable high efficiency, low turn-on voltage and minor efficiency roll-off behavior can be achieved by the strategy of utilizing DPNA-SFX and DOPNA-SFX as HTMs.

\section{Conclusions}

In summary, two new materials, spiro[fluorene-9, $9^{\prime}$-xanthene] (SFX) derivatives, spiro[fluorene-9,9'-xanthene]-2,7-di- $\left(N^{1}, N^{3}\right.$ di-1-naphthalenyl- $N^{1}, N^{3}$-diphenyl-1,3-benzenediamine) (DPNASFX) and spiro[fluorene-9,9'-xanthene]-2', $7^{\prime}$-di- $\left(N^{1}, N^{3}\right.$-di-1naphthalenyl- $N^{1}, N^{3}$-diphenyl-1,3-benzenediamine) were designed, synthesized, and characterized completely. The green PHOLEDs using DPNA-SFX and DOPNA-SFX as the hole-transporting material exhibited maximum EQE values of $24.7 \%$ and $23.6 \%$, respectively. Moreover, the red PHOLEDs with DPNA-SFX achieved the highest EQE of $34.7 \%$ and the EQE at $1000 \mathrm{~cd} \mathrm{~m}^{-2}$ maintained $96 \%$ of its peak value. To the best of our knowledge, these performances are among the highest efficiencies for pure red PHOLEDs. This research work suggests that the SFX-core based derivatives show great potential for application as good hole-transporting materials in PHOLED displays with high EQE and low turn-on voltage as well as low efficiency roll-off.

\section{Experimental section}

\section{General information}

${ }^{1} \mathrm{H}$ and ${ }^{13} \mathrm{C}$ NMR spectra were acquired using a Bruker AVANCE $500 \mathrm{MHz}$ NMR spectrometer. UV-Vis spectra were obtained using a PerkinElmer Lambda 750 spectrophotometer. Fluorescence and phosphorescence spectra at room temperature and $77 \mathrm{~K}$ were recorded using a Horiba Fluorolog-3 in chromatographically pure DCM. Density functional theory (DFT) calculations were performed using the 6-31g(d,p) basis set with Gaussian 09 package. Thermo-gravimetric analysis (TGA) and differential scanning calorimetry (DSC) were carried out using a METTLER TOLEDO TGA/DSC1 system with the samples under pure nitrogen at a heating rate of $10{ }^{\circ} \mathrm{C} \mathrm{min}^{-1}$. A typical threeelectrode configuration was applied in cyclic voltammetry (CV) measurements, with $\mathrm{Ag} / \mathrm{AgNO}_{3}\left(0.1 \mathrm{M}, \mathrm{CH}_{3} \mathrm{CN}\right)$ as the reference electrode, glass carbon as the working electrode and platinum wire as the counter electrode.

\section{Synthetic details}

5-chloro- $N^{1}, N^{3}$-di-1-naphthalenyl- $N^{1}, N^{3}$-diphenyl-1,3-benzenediamine (DPNA-Cl). 1,3-Dibromo-5-chlorobenzene $(10.8 \mathrm{~g}$, $40 \mathrm{mmol}), N$-phenyl-1-naphthylamine (11.68 g, $53.2 \mathrm{mmol})$ and sodium tert-butoxide $(11.52 \mathrm{~g}, 120 \mathrm{mmol})$ were added into a $250 \mathrm{~mL}$ round flask and dissolved in dry toluene $(100 \mathrm{~mL})$ by magnetic stirring. Then, dichlorobis[di-tert-butyl(4-dimethylaminophenyl)phosphino]palladium(II) $(0.848 \mathrm{~g}, 1.2 \mathrm{mmol})$ was added into the container quickly. The mixture was degassed under a nitrogen atmosphere for $20 \mathrm{~min}$ and heated to reflux temperature. After overnight reaction, the mixture was filtrated to remove the base and catalysts, washed with dichloromethane $(200 \mathrm{~mL})$ several times, followed by evaporation. $11.6 \mathrm{~g}$ of white solid was obtained by silica gel column chromatography (petroleum ether/dichloromethane $=10: 1$ ). Yield 53\%. ${ }^{1} \mathrm{H}$ NMR $\left(400 \mathrm{MHz}, \mathrm{CDCl}_{3}\right) \delta 7.87(\mathrm{~s}, 1 \mathrm{H}), 7.85(\mathrm{~s}, 2 \mathrm{H}), 7.83(\mathrm{~s}, 1 \mathrm{H}), 7.72$ $(\mathrm{s}, 1 \mathrm{H}), 7.70(\mathrm{~s}, 1 \mathrm{H}), 7.50-7.45(\mathrm{~m}, 2 \mathrm{H}), 7.40(\mathrm{~s}, 1 \mathrm{H}), 7.38(\mathrm{~d}, J=$ $0.7 \mathrm{~Hz}, 2 \mathrm{H}), 7.36(\mathrm{~s}, 1 \mathrm{H}), 7.24(\mathrm{~d}, J=0.9 \mathrm{~Hz}, 1 \mathrm{H}), 7.22(\mathrm{~d}, J=$ $1.0 \mathrm{~Hz}, 1 \mathrm{H}), 7.06$ (d, $J=1.9 \mathrm{~Hz}, 1 \mathrm{H}), 7.05$ (d, $J=1.2 \mathrm{~Hz}, 2 \mathrm{H}), 7.03$ $(\mathrm{s}, 1 \mathrm{H}), 6.90(\mathrm{~s}, 2 \mathrm{H}), 6.88(\mathrm{~s}, 2 \mathrm{H}), 6.87(\mathrm{~s}, 1 \mathrm{H}), 6.85(\mathrm{~d}, J=1.0 \mathrm{~Hz}$, $1 \mathrm{H}), 6.44(\mathrm{t}, J=2.0 \mathrm{~Hz}, 1 \mathrm{H}), 6.41(\mathrm{~d}, J=2.0 \mathrm{~Hz}, 2 \mathrm{H})$.

MALDI-TOF-MS: $\mathrm{m} / z[\mathrm{M}+\mathrm{H}]^{+}$calcd, 546.19; found, 547.51. Anal. Calcd for $\mathrm{C}_{38} \mathrm{H}_{27} \mathrm{ClN}_{2}$ : C, 83.43; H, 4.97; Cl, 6.48; N, 5.12. Found: C, 83.41; H, 4.97; Cl, 6.47; N, 5.13.

$N^{1}, N^{3}$-di-1-naphthalenyl- $N^{1}, N^{3}$-diphenyl-5-(4,4,5,5-tetramethyl1,3,2-dioxaborolan-2-yl)-1,3-benzenediamine (DPNA-borate).

DPNA-Cl (9.84 g, $18 \mathrm{mmol}$ ) and bis(pinacolato)diboron (5.48 g, $21.6 \mathrm{mmol})$ were added to dry 1,4-dioxane (100 mL). Potassium acetate $(5.30 \mathrm{~g}, \quad 54 \mathrm{mmol}), \quad$ tris(dibenzylideneacetone) dipalladium (0.99 g, $1.08 \mathrm{mmol}$ ) and 2-dicyclohexylphosphino$2^{\prime}, 4^{\prime}, 6^{\prime}$-triisoprophylbiphenyl (1.03 g, $2.16 \mathrm{mmol}$ ) were added to the container quickly under a nitrogen atmosphere. The mixture was heated to reflux temperature and stirred overnight. After the reaction, the mixture was filtrated, washed with dichloromethane $(100 \mathrm{~mL})$, followed by evaporation. The residue was subjected to silica gel column chromatography (petroleum ether/dichloromethane $=4: 1$ ) to obtain $10.33 \mathrm{~g}$ of yellow solid. Yield 90\%. ${ }^{1} \mathrm{H}$ NMR $\left(300 \mathrm{MHz}, \mathrm{CDCl}_{3}\right) \delta 7.84(\mathrm{~d}, J=8.6 \mathrm{~Hz}, 4 \mathrm{H})$, $7.66(\mathrm{~d}, J=8.2 \mathrm{~Hz}, 2 \mathrm{H}), 7.47-7.40(\mathrm{~m}, 2 \mathrm{H}), 7.39-7.27(\mathrm{~m}, 4 \mathrm{H}), 7.22$ $(\mathrm{d}, J=0.9 \mathrm{~Hz}, 1 \mathrm{H}), 7.20(\mathrm{~d}, J=0.9 \mathrm{~Hz}, 1 \mathrm{H}), 7.11(\mathrm{~d}, J=2.2 \mathrm{~Hz}, 2 \mathrm{H})$, 7.05-6.97 (m, 4H), 6.84-6.74 (m, 7H), 1.21 (s, 12H).

MALDI-TOF-MS: $\mathrm{m} / z[\mathrm{M}+\mathrm{H}]^{+}$calcd, 638.31; found, 639.47. Anal. Calcd for $\mathrm{C}_{44} \mathrm{H}_{39} \mathrm{BN}_{2} \mathrm{O}_{2}$ : C, 82.75; H, 6.16; B, 1.69; N, 4.39; O, 5.01. Found: C, 82.71; H, 6.18; B, 1.68; N, 4.38; O, 4.99.

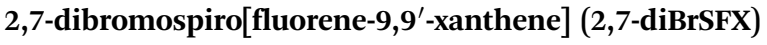

A $100 \mathrm{~mL}$ round flask was charged with 2,7-dibromofluorenone (14.58 g, $43.14 \mathrm{mmol}$ ), phenol (40.6 g, $431.4 \mathrm{mmol}$ ) and methane sulfonic acid (16.93 g, $172.6 \mathrm{mmol})$. The mixture was heated at $150{ }^{\circ} \mathrm{C}$ under a nitrogen atmosphere to carry out the reaction for $24 \mathrm{~h}$. Then, the reaction mixture in the flask was slowly poured into water $(50 \mathrm{~mL})$ and extracted three times with $200 \mathrm{~mL}$ of dichloromethane. After this, the extracts were collected, dried over $\mathrm{MgSO}_{4}$ and evaporated; the residue was subjected to silica gel column chromatography (petroleum ether/dichloromethane $=4: 1)$ to obtain $15.01 \mathrm{~g}$ of white solid. Yield 71\%. ${ }^{1} \mathrm{H}$ NMR (500 MHz, $\left.\mathrm{CDCl}_{3}\right) \delta 7.63(\mathrm{~d}, J=8.1 \mathrm{~Hz}, 2 \mathrm{H})$, $7.50(\mathrm{dd}, J=8.1,1.8 \mathrm{~Hz}, 2 \mathrm{H}), 7.27(\mathrm{~s}, 2 \mathrm{H}), 7.24(\mathrm{dd}, J=4.6$, $1.0 \mathrm{~Hz}, 4 \mathrm{H}), 6.85-6.80$ (m, 2H), 6.40-6.36 (m, 2H). 
MALDI-TOF-MS: $m / z[\mathrm{M}+\mathrm{H}]^{+}$calcd, 487.94; found, 488.65 . Anal. Calcd for $\mathrm{C}_{25} \mathrm{H}_{14} \mathrm{Br}_{2} \mathrm{O}$ : C, 61.24; $\mathrm{H}, 2.88$; Br, 32.60; O, 3.26. Found: C, 61.19; H, 2.88; Br, 32.62; O, 3.27.

\section{$2^{\prime}, 7^{\prime}$-dibromospiro[fluorene-9,9'-xanthene] $\left(2^{\prime}, 7^{\prime}\right.$-diBrSFX $)$}

A $100 \mathrm{~mL}$ round flask was charged with $9 H$-fluoren-9-one $(2.85 \mathrm{~g}$, $15.8 \mathrm{mmol})$, 4-bromophenol $(16.4 \mathrm{~g}, 94.8 \mathrm{mmol})$ and methane sulfonic acid $(6.2 \mathrm{~g}, 63.2 \mathrm{mmol})$. The mixture was heated at $150{ }^{\circ} \mathrm{C}$ under a nitrogen atmosphere to carry out the reaction for $24 \mathrm{~h}$. Then, the reaction mixture in the flask was slowly poured into water $(50 \mathrm{~mL})$ and extracted three times with dichloromethane $(200 \mathrm{~mL})$. After this, the extracts were collected, dried over $\mathrm{MgSO}_{4}$ and evaporated; the residue was subjected to silica gel column chromatography (petroleum ether/dichloromethane $=4: 1$ ) to obtain $4.88 \mathrm{~g}$ of white solid. Yield $63 \% .{ }^{1} \mathrm{H}$ NMR $(400 \mathrm{MHz}$, $\left.\mathrm{CDCl}_{3}\right) \delta 7.81(\mathrm{~d}, J=7.6 \mathrm{~Hz}, 2 \mathrm{H}), 7.42(\mathrm{td}, J=7.5,1.0 \mathrm{~Hz}, 2 \mathrm{H}), 7.30$ $(\mathrm{d}, J=2.4 \mathrm{~Hz}, 1 \mathrm{H}), 7.27(\mathrm{t}, J=2.0 \mathrm{~Hz}, 2 \mathrm{H}), 7.25(\mathrm{~d}, J=1.0 \mathrm{~Hz}, 1 \mathrm{H})$, 7.12 (dd, $J=15.1,8.2 \mathrm{~Hz}, 4 \mathrm{H}), 6.47$ (d, $J=2.4 \mathrm{~Hz}, 2 \mathrm{H})$.

MALDI-TOF-MS: $m / z[\mathrm{M}+\mathrm{H}]^{+}$calcd, 487.94; found, 488.63 . Anal. Calcd for $\mathrm{C}_{25} \mathrm{H}_{14} \mathrm{Br}_{2} \mathrm{O}$ : C, 61.24; H, 2.88; Br, 32.60; O, 3.26. Found: C, 61.21; H, 2.86; Br, 32.63; O, 3.28.

Spiro[fluorene-9,9'-xanthene]-2,7-di-( $\left(N^{1}, N^{3}\right.$-di-1-naphthalenyl- $N^{1}$, $\boldsymbol{N}^{3}$-diphenyl-1,3-benzenediamine) (DPNA-SFX).

DPNA-borate (3.82 g, $6 \mathrm{mmol})$ and 2,7-diBrSFX (1.47 g, $3 \mathrm{mmol})$ were added into a $250 \mathrm{~mL}$ round flask and dissolved in dry toluene $(80 \mathrm{~mL})$ by magnetic stirring. Potassium carbonate $(1.24 \mathrm{~g}, 9 \mathrm{mmol})$ was dissolved in $20 \mathrm{~mL}$ of water and poured into the round flask. Then, dichlorobis[di-tert-butyl(4-dimethylaminophenyl)phosphino]palladium(II) (0.064 g, $0.09 \mathrm{mmol})$ was added into the container quickly. The mixture was degassed under a nitrogen atmosphere for $20 \mathrm{~min}$ and heated to $110{ }^{\circ} \mathrm{C}$. After overnight reaction, the mixture was filtered, poured into water and extracted with dichloromethane $(200 \mathrm{~mL}) .2 .78 \mathrm{~g}$ of white solid was obtained by silica gel column chromatography (petroleum ether/dichloromethane $=4: 1$ ). Yield 69\%. ${ }^{1} \mathrm{H}$ NMR $\left(400 \mathrm{MHz}, \mathrm{CDCl}_{3}\right) \delta 7.83(\mathrm{~d}, J=8.6 \mathrm{~Hz}, 8 \mathrm{H}), 7.66(\mathrm{~d}, J=8.2 \mathrm{~Hz}, 4 \mathrm{H})$, $7.54(\mathrm{~d}, J=7.9 \mathrm{~Hz}, 2 \mathrm{H}), 7.42$ (ddd, $J=8.2,6.9,1.0 \mathrm{~Hz}, 4 \mathrm{H}), 7.36-$ 7.27 (m, 8H), 7.17 (dddd, $J=14.9,9.7,7.8,1.3 \mathrm{~Hz}, 10 \mathrm{H}$ ), 7.05-6.98 $(\mathrm{m}, 8 \mathrm{H}), 6.96(\mathrm{~d}, J=1.3 \mathrm{~Hz}, 2 \mathrm{H}), 6.90-6.77(\mathrm{~m}, 12 \mathrm{H}), 6.65-6.60(\mathrm{~m}$, $2 \mathrm{H}), 6.58$ (dd, $J=3.6,1.5 \mathrm{~Hz}, 6 \mathrm{H}), 6.25(\mathrm{dd}, J=7.9,1.2 \mathrm{~Hz}, 2 \mathrm{H})$. ${ }^{13} \mathrm{C}$ NMR $\left(400 \mathrm{MHz}, \mathrm{CDCl}_{3}\right) \delta 155.23,151.56,149.16,148.05$, $143.25,142.61,141.34,138.51,135.27,131.12,128.95,128.45$, $128.02,127.61,127.04,126.94,126.48,126.36,126.25,126.08$, $125.03,124.40,124.26,123.29,121.78,121.62,119.96,116.79$, 114.17, 113.94, 54.46. MALDI-TOF-MS: $m / z[\mathrm{M}+\mathrm{H}]^{+}$calcd, 1352.54; found, 1353.55. Anal. Calcd for $\mathrm{C}_{101} \mathrm{H}_{64} \mathrm{~N}_{4} \mathrm{O}$ : C, 89.68; H, 5.06; N, 4.14; O, 1.18. Found: C, 89.31; H, 5.05; $\mathrm{N}, 4.14 ; \mathrm{O}, 1.17$.

Spiro[fluorene-9,9'-xanthene]-2', $7^{\prime}-\mathrm{di}$ - $\left(N^{\mathbf{1}}, N^{3}\right.$-di-1-naphthalenyl$N^{1}, N^{3}$-diphenyl-1,3-benzenediamine) (DOPNA-SFX)

DPNA-borate (4.7 g, $7 \mathrm{mmol}$ ) and 2,7-diBrSFX (1.72 g, $3.5 \mathrm{mmol})$ were added into a $250 \mathrm{~mL}$ round flask and dissolved in $80 \mathrm{~mL}$ of dry toluene by magnetic stirring. Potassium carbonate $(1.45 \mathrm{~g}$, $10.5 \mathrm{mmol})$ was dissolved in water $(20 \mathrm{~mL})$ and poured into the round flask. Then, dichlorobis[di-tert-butyl(4-dimethylaminophenyl)phosphino]palladium(II) (0.074 g, $0.11 \mathrm{mmol})$ was added into the container quickly. The mixture was degassed under a nitrogen atmosphere for $20 \mathrm{~min}$ and heated to $110{ }^{\circ} \mathrm{C}$. After overnight reaction, the mixture was filtered, poured into water and extracted with dichloromethane $(200 \mathrm{~mL}) .3 .55 \mathrm{~g}$ of white solid was obtained by silica gel column chromatography (petroleum ether/dichloromethane $=4: 1$ ). Yield 75\%. ${ }^{1} \mathrm{H}$ NMR $\left(400 \mathrm{MHz}, \mathrm{CDCl}_{3}\right) \delta 7.85(\mathrm{~d}, J=8.2 \mathrm{~Hz}, 4 \mathrm{H}), 7.78(\mathrm{~d}, J=8.4 \mathrm{~Hz}$, $4 \mathrm{H}), 7.66(\mathrm{dd}, J=16.1,7.9 \mathrm{~Hz}, 6 \mathrm{H}), 7.44(\mathrm{dd}, J=11.1,4.0 \mathrm{~Hz}$, $4 \mathrm{H}), 7.31$ (dd, $J=15.7,7.8 \mathrm{~Hz}, 8 \mathrm{H}), 7.27$ (d, $J=2.1 \mathrm{~Hz}, 1 \mathrm{H}), 7.25$ $(\mathrm{d}, J=1.8 \mathrm{~Hz}, 1 \mathrm{H}), 7.16(\mathrm{~d}, J=6.6 \mathrm{~Hz}, 4 \mathrm{H}), 7.07(\mathrm{~d}, J=1.8 \mathrm{~Hz}$, $1 \mathrm{H}), 7.05-7.03(\mathrm{~m}, 3 \mathrm{H}), 7.00-6.95(\mathrm{~m}, 8 \mathrm{H}), 6.90(\mathrm{t}, J=5.8 \mathrm{~Hz}$, $4 \mathrm{H}), 6.80(\mathrm{dd}, J=14.4,7.4 \mathrm{~Hz}, 12 \mathrm{H}), 6.52(\mathrm{t}, J=1.9 \mathrm{~Hz}, 2 \mathrm{H}), 6.34$ $(\mathrm{d}, J=2.0 \mathrm{~Hz}, 4 \mathrm{H}), 6.20(\mathrm{~d}, J=1.8 \mathrm{~Hz}, 2 \mathrm{H}) .{ }^{13} \mathrm{C} \mathrm{NMR}(400 \mathrm{MHz}$, $\left.\mathrm{CDCl}_{3}\right) \delta 154.07,151.17,149.19,148.03,143.23,141.76,139.52$, $136.11,135.32$, 131.25, 128.95, 128.44, 128.25, 127.92, 127.11, 126.73 , 126.50, 126.36, 126.25, 126.07, 125.98, 125.39, 124.39, $121.78,121.59,119.82,116.83,113.65,113.32$, 54.49. MALDITOF-MS: $m / z[\mathrm{M}+\mathrm{H}]^{+}$calcd, 1352.54; found, 1353.53. Anal. Calcd for $\mathrm{C}_{101} \mathrm{H}_{64} \mathrm{~N}_{4} \mathrm{O}$ : C, 89.62; H, 5.06; N, 4.14; O, 1.18. Found: C, 89.24; H, 5.03; N, 4.16; O, 1.16 .

\section{Device fabrication and measurements}

All the materials except DPNA-SFX and DOPNA-SFX for multilayer PHOLED fabrication and ITO-coated glass substrates were purchased from commercial sources. The ITO-coated glass substrates were washed with acetone, deionized water and isopropanol in order and put into a UV-ozone environment for $20 \mathrm{~min}$. The deposition process of all organic layers and metal electrode was performed under vacuum $\left(\sim 8 \times 10^{-7} \mathrm{~Pa}\right)$. The characterization of PHOLED performance including current density-voltageluminance $(J-V-L)$ curves, electroluminescence (EL) spectra and Commission Internationale de ĺEclairage (CIE) coordinates were carried out using a Keithley 2400 semiconductor characterization system with BM-7A luminance colorimeter and PR-788 photometer. Further measurements were also conducted using equipment with calibrated integrating spheres and with the device's substrate edges masked. The external quantum efficiency of all the fabricated devices were calculated according to electroluminescence performance and EL spectra.

All the measurements except device lifetime measurements were conducted in ambient environment without further protection at room temperature. Device stability of PHOLEDs was evaluated by collecting time dependent luminance data at a constant current density and constant initial luminance. The lifetime measurements were carried out in a glovebox with encapsulation.

\section{Conflicts of interest}

There are no conflicts to declare.

\section{Acknowledgements}

This work was financially supported by the Key-Area Research and Development Program of Guangdong Province (2019B010924003), 
Guangdong Basic and Applied Basic Research Foundation (2020B1515120030), Shenzhen Peacock Plan (KQTD2014 062714543296), Shenzhen Engineering Research Center (Shenzhen development and reform commission [2018]1410), and Shenzhen Science and Technology Research Grant (JCYJ20180302153451987).

\section{References}

1 J. Kido, M. Kimura and K. Nagai, Science, 1995, 267, 1332.

2 S. Chen, L. Deng, J. Xie, L. Peng, L. Xie, Q. Fan and W. Huang, Adv. Mater., 2010, 22, 5227-5239.

3 Z. Wu and D. Ma, Mater. Sci. Eng., R, 2016, 107, 1-42.

4 Z. Zheng, Q. Dong, L. Gou, J.-H. Su and J. Huang, J. Mater. Chem. C, 2014, 2, 9858-9865.

5 S. Zhang, Q.-L. Xu, J.-C. Xia, Y.-M. Jing, Y.-X. Zheng and J.-L. Zuo, New J. Chem., 2015, 39, 7954-7960.

6 T.-Y. Chu and O.-K. Song, Appl. Phys. Lett., 2007, 90.

7 R. Braveenth, H. W. Bae, I. J. Ko, W. Qiong, Q. P. B. Nguyen, P. G. S. Jayashantha, J. H. Kwon and K. Y. Chai, Org. Electron., 2017, 51, 463-470.

8 S. Zhang, L.-S. Xue, Y.-M. Jing, X. Liu, G.-Z. Lu, X. Liang, H.-Y. Li, Y.-X. Zheng and J.-L. Zuo, Dyes Pigm., 2015, 118, 1-8.

9 A. M. Thaengthong, S. Saengsuwan, S. Jungsuttiwong, T. Keawin, T. Sudyoadsuk and V. Promarak, Tetrahedron Lett., 2011, 52, 4749-4752.

10 S. Jhulki and J. N. Moorthy, J. Mater. Chem. C, 2018, 6, 8280-8325.

11 J. Li, C. Ma, J. Tang, C.-S. Lee and S. Lee, Chem. Mater., 2005, 17, 615-619.

12 Z. Li, Z. Wu, W. Fu, D. Wang, P. Liu, B. Jiao, X. Lei, G. Zhou and Y. Hao, Electron. Mater. Lett., 2013, 9, 655-661.

13 R. Griniene, J. V. Grazulevicius, K. Y. Tseng, W. B. Wang, J. H. Jou and S. Grigalevicius, Synth. Met., 2011, 161, 2466-2470.

14 O. Usluer, S. Demic, D. A. M. Egbe, E. Birckner, C. Tozlu, A. Pivrikas, A. M. Ramil and N. S. Sariciftci, Adv. Funct. Mater., 2010, 20, 4152-4161.

15 H. Kanai, S. Ichinosawa and Y. Sato, Synth. Met., 1997, 91, 195-196.

16 J. Zhuang, W. Su, W. Li, Y. Zhou, Q. Shen and M. Zhou, Org. Electron., 2012, 13, 2210-2219.

17 B. Liu, J. Zhao, C. Luo, F. Lu, S. Tao and Q. Tong, J. Mater. Chem. C, 2016, 4, 2003-2010.

18 Q. D. Liu, J. Lu, J. Ding, M. Day, Y. Tao, P. Barrios, J. Stupak, K. Chan, J. Li and Y. Chi, Adv. Funct. Mater., 2007, 17, 1028-1036.

19 X.-Y. Liu, Y.-J. Zhang, X. Fei, Q. Ran, M.-K. Fung and J. Fan, J. Mater. Chem. C, 2019, 7, 1370-1378.

20 Q. P. Nguyen, S. J. Baek, M. J. Kim, N. Y. Shin, G. W. Kim, D. C. Choe, J. H. Kwon and K. Y. Chai, Molecules, 2014, 19, 14247-14256.

21 T. L. Wu, S. Y. Liao, P. Y. Huang, Z. S. Hong, M. P. Huang, C. C. Lin, M. J. Cheng and C. H. Cheng, ACS Appl. Mater. Interfaces, 2019, 11, 19294-19300.
22 S.-h. Ye, L. Li, M. Zhang, Z. Zhou, M.-h. Quan, L.-F. Guo, Y. Wang, M. Yang, W.-Y. Lai and W. Huang, J. Mater. Chem. C, 2017, 5, 11937-11946.

23 H. Fukagawa, T. Shimizu, H. Kawano, S. Yui, T. Shinnai, A. Iwai, K. Tsuchiya and T. Yamamoto, J. Phys. Chem. C, 2016, 120, 18748-18755.

24 J. Kwak, Y.-Y. Lyu, S. Noh, H. Lee, M. Park, B. Choi, K. Char and C. Lee, Thin Solid Films, 2012, 520, 7157-7163.

25 Z. Zhong, X. Wang, T. Guo, J. Cui, L. Ying, J. Peng and Y. Cao, Org. Electron., 2018, 53, 35-42.

26 X.-Y. Liu, X. Tang, Y. Zhao, D. Zhao, J. Fan and L.-S. Liao, J. Mater. Chem. C, 2018, 6, 1023-1030.

27 M. Romain, C. Quinton, D. Tondelier, B. Geffroy, O. Jeannin, J. Rault-Berthelot and C. Poriel, J. Mater. Chem. C, 2016, 4, 1692-1703.

28 M. Romain, D. Tondelier, B. Geffroy, A. Shirinskaya, O. Jeannin, J. Rault-Berthelot and C. Poriel, Chem. Commun., 2015, 51, 1313-1315.

29 X.-D. Zhu, Y.-L. Zhang, Y. Yuan, Q. Zheng, Y.-J. Yu, Y. Li, Z.-Q. Jiang and L.-S. Liao, J. Mater. Chem. C, 2019, 7, 6714-6720.

30 C. Poriel and J. Rault-Berthelot, J. Mater. Chem. C, 2017, 5, 3869-3897.

31 L.-H. Xie, F. Liu, C. Tang, X.-Y. Hou, Y.-R. Hua, Q.-L. Fan and W. Huang, Org. Lett., 2006, 8, 2787-2790.

32 H. Li, K. Fu, A. Hagfeldt, M. Gratzel, S. G. Mhaisalkar and A. C. Grimsdale, Angew. Chem., 2014, 53, 4085-4088.

33 B.-Y. Ren, D.-K. Zhong, Y.-G. Sun, X.-H. Zhao, Q.-J. Zhang, Y. Liu, M. Jurow, M.-L. Sun, Z.-S. Zhang and Y. Zhao, Org. Electron., 2016, 36, 140-147.

34 M. Sun, R. Xu, L. Xie, Y. Wei and W. Huang, Chin. J. Chem., 2015, 33, 815-827.

35 D. P. Tabor, V. A. Chiykowski, P. Friederich, Y. Cao, D. J. Dvorak, C. P. Berlinguette and A. Aspuru-Guzik, Chem. Sci., 2019, 10, 8360-8366.

36 X.-H. Zhao, Y.-N. Xu, J.-X. Wu, G.-D. Zou, X.-W. Zhang, L.-H. Xie, J.-F. Zhao, C.-M. Han, X. Hui and J.-J. Zhang, Dyes Pigm., 2019, 168, 228-234.

37 L. Calio, S. Kazim, M. Gratzel and S. Ahmad, Angew. Chem., 2016, 55, 14522-14545.

38 H.-T. Cao, C.-S. Hong, D.-Q. Ye, L.-H. Liu, L.-H. Xie, S.-F. Chen, C. Sun, S.-S. Wang, H.-M. Zhang and W. Huang, J. Mol. Struct., 2019, 1196, 132-138.

39 H.-j. Jiang, J. Sun, K. Yuan and Q.-w. Zhang, Synth. Met., 2014, 197, 217-224.

40 X. Liang, K. Wang, R. Zhang, K. Li, X. Lu, K. Guo, H. Wang, Y. Miao, H. Xu and Z. Wang, Dyes Pigm., 2017, 139, 764-771.

41 M. Maciejczyk, A. Ivaturi and N. Robertson, J. Mater. Chem. A, 2016, 4, 4855-4863.

42 B. Xu, D. Bi, Y. Hua, P. Liu, M. Cheng, M. Grätzel, L. Kloo, A. Hagfeldt and L. Sun, Energy Environ. Sci., 2016, 9, 873-877.

43 V. A. Chiykowski, Y. Cao, H. Tan, D. P. Tabor, E. H. Sargent, A. Aspuru-Guzik and C. P. Berlinguette, Angew. Chem., Int. Ed., 2018, 57, 15529-15533.

44 Z. Jiang, T. Ye, C. Yang, D. Yang, M. Zhu, C. Zhong, J. Qin and D. Ma, Chem. Mater., 2011, 23, 771-777. 
45 D.-H. Lee, Y.-P. Liu, K.-H. Lee, H. Chae and S. M. Cho, Org. Electron., 2010, 11, 427-433.

46 H. Sasabe, E. Gonmori, T. Chiba, Y.-J. Li, D. Tanaka, S.-J. Su, T. Takeda, Y.-J. Pu, K.-I. Nakayama and J. Kido, Chem. Mater., 2008, 20, 5951-5953.

47 J. Li, D. Liu, Y. Li, C.-S. Lee, H.-L. Kwong and S. Lee, Chem. Mater., 2005, 17, 1208-1212.

48 C.-H. Chen, L.-C. Hsu, P. Rajamalli, Y.-W. Chang, F.-I. Wu, C.-Y. Liao, M.-J. Chiu, P.-Y. Chou, M.-J. Huang, L.-K. Chu and C.-H. Cheng, J. Mater. Chem. C, 2014, 2, 6183-6191.

49 L. S. Cui, Y. Liu, X. Y. Liu, Z. Q. Jiang and L. S. Liao, ACS Appl. Mater. Interfaces, 2015, 7, 11007-11014.

50 B. Jiang, X. Ning, S. Gong, N. Jiang, C. Zhong, Z.-H. Lu and C. Yang, J. Mater. Chem. C, 2017, 5, 10220-10224.
51 B. Jiang, C. Zhao, X. Ning, C. Zhong, D. Ma and C. Yang, Adv. Opt. Mater., 2018, 6, 1800108.

52 K. H. Kim, S. Lee, C. K. Moon, S. Y. Kim, Y. S. Park, J. H. Lee, J. Woo Lee, J. Huh, Y. You and J. J. Kim, Nat. Commun., 2014, 5, 4769.

53 C. Y. Kuei, W. L. Tsai, B. Tong, M. Jiao, W. K. Lee, Y. Chi, C. C. Wu, S. H. Liu, G. H. Lee and P. T. Chou, Adv. Mater., 2016, 28, 2795-2800.

54 J. H. Lee, H. Shin, J. M. Kim, K. H. Kim and J. J. Kim, ACS Appl. Mater. Interfaces, 2017, 9, 3277-3281.

55 X. Y. Liu, F. Liang, Y. Yuan, L. S. Cui, Z. Q. Jiang and L. S. Liao, Chem. Commun., 2016, 52, 8149-8151.

56 C. H. Shih, P. Rajamalli, C. A. Wu, W. T. Hsieh and C. H. Cheng, ACS Appl. Mater. Interfaces, 2015, 7, 10466-10474.

57 C.-H. Shih, P. Rajamalli, C.-A. Wu, M.-J. Chiu, L.-K. Chu and C.-H. Cheng, J. Mater. Chem. C, 2015, 3, 1491-1496. 